\title{
ROX index in COVID-19 patients - is it the answer?
}

\section{To the Editor}

As the world stands witness to the havoc caused by the COVID-19 pandemic, the shortage of mechanical ventilators a common peril in the already stressed healthcare system around the globe. HFNC (high flow nasal cannula) is being used now in most ICU settings to prevent ventilator requirements in patients with type 1 respiratory failure. It allows high flows and fractions of inspired oxygen $\left(\mathrm{FiO}_{2}\right)$ at a more physiological level of temperature and humidity. The mechanism of HFNC includes small pliable nasal prongs which increase the comfort of the patient, humidification facilitates expectoration of secretions, washout of nasopharyngeal dead space that improves the efficiency of ventilation, high flow rates that help in reliable delivery of $\mathrm{FiO}_{2}$, and a small continuous positive airway pressure effect. The prediction of the success of HFNC is recently been done by using the ROX index.

ROX index is defined as the ratio of pulse oximetry/fraction of inspired oxygen $\left(\mathrm{SpO}_{2} / \mathrm{FiO}_{2}\right)$ to respiratory rate (RR). This index has been used in emergency [1] to predict intubation as well in patients with pneumonia who are having acute respiratory failure [2]. The studies on the ROX index have measured different time intervals post-initiation of HFNC and suggested either 6 hours or 12 hours value as the most sensitive predictor for the probability of intubation $[2,3]$. Recently a new index modified ROX has been devised in a study. Modified ROX is defined as (respiratory rate oxygenation-heart rate) the ratio of ROX index over HR (beats/min) and multiplying by a factor of 100 [4]. This study showed that that modified ROX helped in the early identification of HFNC failure, as early as 1-2 hours.
WHY? - a scoring system such as ROX is required in an emergency or critical care setting to make it easier for the physician to decide on the institution of mechanical ventilation. It has been seen in multiple studies $[5,6]$ that late failure of NIV has lead to adverse outcomes and increased mortality, the reason being increased disease progression with increased respiratory rate. During NIV trial in severe respiratory disease, if high driving pressures are used for ventilation; lung injury occurs due to over-distension of the healthy lung. This phenomenon is known as self-inflicted lung injury. Patient-ventilator dyssynchrony also plays a major role in lung injury. There are not many studies comparing late HFNC failure (> 48 hours) with mortality. The study done by B. J. Kang et al. [7] showed late HFNC failure was associated with higher mortality when compared to early HFNC failure. The reason for the same being that delayed intubation can lead to further disease progression causing respiratory muscle fatigue and cardiac dysfunction which cumulatively lead to increased mortality in ICU. Hence from these findings, we can analyze the importance of an objective prediction score which will help in the early identification of HFNC failure so that mortality can be reduced.

\section{Role of ROX in COVID-19}

ROX index was being used earlier in acute respiratory failure in pneumonia. Since the arrival of COVID-19, it has gained newfound interest. L.A. Suliman et al. [8] in their study validated the diagnostic accuracy of ROX in COVID-19 pneumonia. ROX index has been used in the emergency department which is generally the first point of contact in tertiary care hospi- 
Table 1. ROX index and HFNC based trials

\begin{tabular}{|c|c|c|c|}
\hline Study & Type of study & Number of patients (n) & Interventions \& remarks \\
\hline $\begin{array}{l}\text { Goh, K.J } \\
\text { et al. }(2020)\end{array}$ & Prospective observational & 145 & $\begin{array}{l}\text { Introduced a new index ROX-HR. Helped in early } \\
\text { prediction of HFNC failure, as early as } 1-2 \text { hours }\end{array}$ \\
\hline $\begin{array}{l}\text { Panadero C } \\
\text { et al. (2020) }\end{array}$ & Retrospective observational & 196 & $\begin{array}{l}\text { After initiating HFNC, a ROX index below } 4.94 \text { predicts } \\
\text { the need for intubation in COVID-19 patients }\end{array}$ \\
\hline $\begin{array}{l}\text { Lee CU } \\
\text { et al. (2020) }\end{array}$ & Retrospective observational & 2862 & $\begin{array}{c}\text { ROX index }<10 \text { is an independent prognostic factor } \\
\text { for 28-day mortality in patients with sepsis } \\
\text { or septic shock. }\end{array}$ \\
\hline $\begin{array}{l}\text { María Laura Vega } \\
\text { et al. (2021) }\end{array}$ & $\begin{array}{l}\text { Multi-centre retrospective } \\
\text { observational analysis of } \\
\text { prospectively collected data. }\end{array}$ & 120 & $\begin{array}{c}\text { The ROX index at } 12 \text { hours of }<5.99 \text { was associated } \\
\text { with HFNC failure. This value was higher than } \\
\text { the non-covid patients, possibly due to different } \\
\text { pathophysiology of the disease per se. }\end{array}$ \\
\hline $\begin{array}{l}\text { Gianstefani A } \\
\text { et al. (2021) }\end{array}$ & Prospective observational & 554 & $\begin{array}{c}\text { They measured the ROX index in emergency setting. } \\
\text { A ROX index value }<25.7 \text { was associated } \\
\text { with hospitalization whereas ROX index }<22.3 \\
\text { was associated with higher } 30 \text {-day mortality }\end{array}$ \\
\hline
\end{tabular}

tals. It has been observed that a lower ROX score was associated with increased hospitalization and increased mortality. A ROX index value $<25.7$ was associated with hospitalization whereas a ROX index $<22.3$ was associated with higher 30-day mortality [1]. Hence ROX index makes the decision-making easier and also helps the clinician to prognosticate early regarding the probable course of illness.

The next question which remains unanswered is what is the earliest and most sensitive time point to predict the effectiveness of the HFNC therapy. Minh hu et al. [3] in a retrospective cohort study compared the ROX index in patients admitted with acute respiratory distress due to COVID-19. They studied the ROX index at 3-time points namely 6 hours, 12 hours, and 24 hours post-initiation of HFNC therapy. They inferred that the ROX index assessed at 6 hours post-HFNC initiation had higher predictability for HFNC failure as compared to other time points. The cut-off for determining success or failure was 5.55 in their study. In another study done by $\mathrm{O}$. Rocca et al. on non-covid patients, the cut-off point was determined to be 4.88 whereas the best predictability regarding the success of HFNC was achieved at 12 hours post initiation which was different from the cut-off of the previous study. Carolina Panadero et al. [9] had retrospectively studied ARDS in COVID-19 patients requiring HFNC. They found that a ROX index $<4.94$ measured between 2 to 6 hours after initiation of HFNC was associated with an increased rate of intubation and hence HFNC failure. This cut-off value was slightly higher than that recorded by
Rocca et al. Maria Laura Vega et al. [10] as a further continuation of the study conducted by Carolina Panadero did a multi-center trial in COVID-19 patients not admitted to ICU. The patients generally had a moderate degree of respiratory failure. They set their cut-off of ROX index higher than O.Rocca et al at 5.99 which was much higher than the cut-off for non-covid patients (4.88). The different cut-offs for COVID-19 pneumonia as compared to other causes of acute respiratory failure are explained by the different pathophysiology of COVID-19 particularly the varied phenotypes. The most commonly associated phenotypes are the classical ARDS, lung injury plus high dead-space related to emboli/diffuse microthrombi, or normal lung with embolism [11]. Maria Laura Vega also found the ROX index measured at 12 hours co-related well with determining the success or failure of HFNC. They argued that 12 hours intervals didn't delay the institution of mechanical ventilation as this is the usual duration in patients having moderate ARDS, as was the case in their study. Table 1 represents various studies using the ROX index and their outcome.

Hence we can see from the above discussion that the cut-off is relatively higher for COVID-19 pneumonia for the ROX index. It is also clearly evident that an early time point for the assessment of ROX is needed in ICU patients compared to patients not admitted to ICU.

\section{Other application of ROX index}

Other than the application of ROX in hypoxaemic respiratory failure, recently it has found its 
role in sepsis. A study done by Che Uk Lee et al. [12] found that the ROX index is the simple index for the prediction of mortality. They found that a ROX index of $\leq 10$ in an emergency can be an independent predictor of mortality in patients with signs of sepsis. They also found that the prognostic performance of ROX was better than qSOFA in sepsis.

\section{Future research}

A well-designed RCT is needed to predict the optimal point of measuring the ROX index to improve outcome in COVID-19 patients. The actual cut-off for determining failure of HFNC by ROX index has not been determined. A well-planned RCT catering to this objective is also desirable.

\section{Conflict of interest}

None declared.

\section{References:}

1. Gianstefani A, Farina G, Salvatore V, et al. Role of ROX index in the first assessment of COVID-19 patients in the emergency department. Intern Emerg Med. 2021; 16(7): 1959-1965, doi: 10.1007/s11739-021-02675-2, indexed in Pubmed: 33646507.

2. Roca O, Messika J, Caralt B, et al. Predicting success of highflow nasal cannula in pneumonia patients with hypoxemic respiratory failure: The utility of the ROX index. J Crit Care. 2016; 35: 200-205, doi: 10.1016/j.jcrc.2016.05.022, indexed in Pubmed: 27481760.

3. Hu M, Zhou Q, Zheng R, et al. Application of high-flow nasal cannula in hypoxemic patients with COVID-19: a retrospective cohort study. BMC Pulm Med. 2020; 20(1): 324, doi: 10.1186/ s12890-020-01354-w, indexed in Pubmed: 33357219.

4. Goh KJ, Chai HZ, Ong TH, et al. Early prediction of high flow nasal cannula therapy outcomes using a modified ROX index incorporating heart rate. J Intensive Care. 2020; 8: 41, doi: 10.1186/s40560-020-00458-z, indexed in Pubmed: $\underline{32587703}$.

5. Moretti M, Cilione C, Tampieri A, et al. Incidence and causes of non-invasive mechanical ventilation failure after initial success. Thorax. 2000; 55(10): 819-825, doi: 10.1136/thorax.55.10.819, indexed in Pubmed: 10992532.

6. Ozyilmaz E, Ugurlu AO, Nava S. Timing of noninvasive ventilation failure: causes, risk factors, and potential remedies. BMC Pulm Med. 2014; 14: 19, doi: 10.1186/1471-2466-14-19, indexed in Pubmed: 24520952.

7. Kang BJu, Koh Y, Lim CM, et al. Failure of high-flow nasal cannula therapy may delay intubation and increase mortality. Intensive Care Med. 2015; 41(4): 623-632, doi: 10.1007/ s00134-015-3693-5, indexed in Pubmed: 25691263.

8. Suliman LA, Abdelgawad TT, Farrag NS, et al. Validity of ROX index in prediction of risk of intubation in patients with COVID-19 pneumonia. Adv Respir Med. 2021; 89(1): 1-7, doi: 10.5603/ARM.a2020.0176, indexed in Pubmed: 33471350.

9. Panadero C, Abad-Fernández A, Rio-Ramirez $\mathrm{M}^{\mathrm{a}} \mathrm{T}$, et al. Highflow nasal cannula for Acute Respiratory Distress Syndrome (ARDS) due to COVID-19. Multidiscip Respir Med. 2020; 15(1): 693, doi: $10.4081 / \mathrm{mrm} .2020 .693$, indexed in Pubmed: 32983456.

10. Vega ML, Dongilli R, Olaizola G, et al. COVID-19 Pneumonia and ROX index: Time to set a new threshold for patients admitted outside the ICU. Pulmonology. 2021 [Epub ahead of print], doi: 10.1016/j.pulmoe.2021.04.003, indexed in Pubmed: $\underline{34049831}$.

11. Grasselli G, Tonetti T, Protti A, et al. collaborators. Pathophysiology of COVID-19-associated acute respiratory distress syndrome: a multicentre prospective observational study. Lancet Respir Med. 2020; 8(12): 1201-1208, doi: 10.1016/S22132600(20)30370-2, indexed in Pubmed: 32861276 .

12. Lee CUk, Jo YH, Lee JH, et al. The index of oxygenation to respiratory rate as a prognostic factor for mortality in Sepsis. Am J Emerg Med. 2021; 45: 426-432, doi: 10.1016/j. ajem.2020.09.052, indexed in Pubmed: $\underline{33039213}$. 